\title{
CATEGORIAS GEOGRÁFICAS: ESTUDO METODOLÓGICO DE ENSINO DA PAISAGEM, TERRITÓRIO E LUGAR.
}

\author{
GEOGRAPHICAL CATEGORIES: METHODOLOGICAL STUDY OF TEACHING THE LANDSCAPE, \\ TERRITORY AND PLACE.
}

Fátima Daniela Carvalho de Sousa 1

\section{RESUMO}

O presente trabalho debruça-se ao estudo dos métodos didáticos para o ensino dos conceitos geográficos: lugar, paisagem, território e região. Partindo do pressuposto de que todos os temas estudados pela Geografia têm como fundamento suas categorias principais, o objetivo proposto é fazer da aprendizagem significativa o principal pilar para a assimilação dos conceitos e; assim, absorver a síntese fundamental para formação do pensamento geográfico, logo entendemos que o estudo de caso apresenta a luz da aprendizagem significativa como abordagem prática dos conceitos. O objeto de estudo é o local de moradia, e a rotina desenvolvida por indivíduos ou por movimentos feitos em comunidade que apresentam reflexos diretos no espaço geográfico e na relação humana estabelecida nele. Através das análises e reflexões das relações estabelecidas entre os agentes e os ambientes de vivencia, foi possível constatar níveis de percepção da essência social construída, e das noções de direito e cidadania subempregados. Observar as lacunas que separam a aprendizagem eficiente, promotora do pensamento crítico e o desemparo das políticas públicas de educação, força a busca por alternativas que driblem os gargalos impostos aos usuários do ensino público. A triangulação entre os documentos bases, o conteúdo programático e a rotina estabelecida nas instituições transbordam informações que traçam prognósticos analíticos eficientes na busca pela significação da aprendizagem proposta nesta discussão.

PALAVRAS-CHAVE: Educação; Categorias; Geografia.

\footnotetext{
${ }^{1}$ Graduanda em Geografia pela PUC-MINAS. E-mail: fatimageoufu@gmail.com
} 


\begin{abstract}
This work aims to study didactic methods for teaching Geography through the categories: place, landscape, territory and region. The aim of this study is to understand a Geography close to people, with the place of residence as the centrality based on a routine developed by individuals in the community. Thus, through geographic categories, it is possible to observe and understand the gaps that separate efficient learning, as well as promote critical thinking and implement public education policies. A triangulation between the documentary bases, the programmatic content and the routine, in the institutions that overflow the information that trace the efficient analytical prognostics in the search of the meaning or of the learning proposed in this discussion.
\end{abstract}

KEYWORDS: Education; Categories; Geography.

\title{
INTRODUÇÃo
}

O papel formativo de uma criança é estabelecido a partir do momento em que as relações sociais são estabelecidas. Rousseau afirma em sua obra 'O Contrato Social', deve-se deixar o processo da descoberta daquilo que está destinado a ser. O autor afirma que o processo de formação deve respeitar todas as etapas. Com isso, compreende o pensamento no ceio do acontecer evolutivo, seja de um indivíduo ou de uma sociedade. Esta, por sua vez, formada por pessoas predestinadas a manter a ordem imposta e estabelecida através do avançar dos conflitos que estruturam e definem as hierarquias de poder. Neste contexto, é altamente questionado o papel do professor na vida do aluno; a escola como instituição do Estado, este mesmo Estado que estabelece leis e normativas de manutenção da paz; é fundamental, avaliar que o principal contato existente entre a nova geração que se forma e o Estado, responsável pela manutenção do contrato social, são a escola e as forças repressivas - polícia. Estas questões fundamentais devem permear o cotidiano das escolas, não somente com os professores, mas de todos os envolvidos no ambiente de aprendizagem. Em muitos, a resposta para estas interrogações vem acompanhada pela ausência de políticas públicas capaz de qualificar e dar condições para atingirmos a máxima da aprendizagem: formar cidadãos.

Compreender o papel da escola na formação do indivíduo é compreender que, talvez este seja o principal elo entre o adolescente - futuro cidadão - com o que chamamos de Estado. Estudar Geografia nos anos iniciais compete discutir sobre o 
processo de intensa transformação social, a materialização da presença do Estado Nação, saber quais ações levaram para a construção do espaço geográfico da forma como está e o que ainda está por vir. Para além da descrição dos elementos geográficos que compõe a paisagem, abordar a Geografia renovada é fundamental para contribuir com a formação crítica do aluno.

"O professor não é um técnico nem um improvisador, mas sim um profissional que pode utilizar o seu conhecimento e a sua experiência para se desenvolver em contextos pedagógicos práticos preexistentes". (SACRISTAN, 1991, p.74)

Neste sentido, a metodologia utilizada é fundamental. A questão é: memorizar cursos de rios, nomes de capitais, de meridianos, de formações morfológicas e tantas outras nomenclaturas desta ciência continuam sendo o principal objetivo? A Geografia crítica defende a busca incessante por respostas que sejam capazes de dar conta dos processos estabelecido na relação homem-natureza, e os efeitos dela na vida concreta. Então, qual seria a melhor abordagem?

As particularidades dos alunos devem ser levadas a cabo em todo processo de aprendizagem, visto que a bagagem de vida e experiência difere de cada indivíduo. Crescer é complexo, e fazer despertar o interesse em aprender é o maior desafio do professor. Por isso, todo questionamento é importante, tantos dos alunos, mas principalmente do professor. Ausubel desenvolveu a teoria do 'aprendizado significativo', que busca dar ao aluno possibilidades de construir o seu próprio caminho rumo à aprendizagem. O principal objetivo é significar o conteúdo proposto pelos currículos base, ultrapassar a fronteira da memorização e não fornecer um conteúdo pronto e acabado; mas, propor caminhos para a descoberta, relacionar o conteúdo com a realidade e com os eventos do cotidiano social (MOREIA \& MASINI, 1982).

O ensino da Geografia, segundo o PCN, deve guiar o aluno na investigação sobre o processo de formação do espaço geográfico, interpretar as interações humanas.

"O espaço geográfico é historicamente produzido pelo homem, enquanto organiza econômica e socialmente sua sociedade" (BRASIL, 2000, p. 109).

A luz da teoria do 'aprendizado significativo', é elementar o diagnóstico das referências conhecidas e das experiências vividas pela classe, elaborar plano de ações que estejam em sintonia com que foi captado. Não são raras as ocasiões em que nos deparamos com algo que já foi estudado, mas, simplesmente perdemos, esquecemos. Isso acontece porque não teve nenhuma conexão com as experiências vividas. É 
urgente superar este método de ensino. É preciso tornar o ensino real, prático e com sentido.

[...] Nem na realidade nem na mente existem conteúdos sem estrutura, nem estruturas vazias de conteúdos. Como afirma Piaget, as estruturas são construídas mediante a estruturação do real. Portanto, para ser significativa e provocar desenvolvimento, a aprendizagem requer que se trabalhe com conteúdos relevantes [...]" (LERNER, 1995, p.93)

Neste contexto, cabe ao professor exercer a função de mediador, ou balizador de contrastes; devendo apresentar, para além do conteúdo programático, um novo mundo de possibilidades capaz de aguçar a curiosidade e a busca por novos mundos e novas descobertas.

Apesar das adversidades, o compromisso com a formação cidadã é combustível para permanecer acreditando que a melhor saída seja a educação. Com isso, a apresentação do conteúdo deve relacionar com o cotidiano do receptor, para que ele ultrapasse os limites da absorção e seja construtor do seu próprio caminho. Atentar ao processo de relacionar o conteúdo com a vida cotidiana é urgente e necessário, garantindo que o exercício de aprender ganhe cor, forma e significado.

O desafio de transmitir conhecimento é algo que compõe o cotidiano dos professores de diversas áreas e níveis de ensino. Apesar das inúmeras teorias, anos de estudos e exaustivos debates na academia, encarar a sala de aula é totalmente diferente de qualquer cenário possível de imaginar.

O ensino da Geografia, por se tratar de uma ciência social aplicada, entra em conflito com o atual cenário do país, em que há desvalorização do pensamento racional e crítico sobre os fatores que compõe e modificam as relações sócio espaciais estabelecidas, especialmente quando abordada em instituições de ensino pública, localizadas em áreas consideradas de vulnerabilidade social. Pois busca incitar a investigação e crítica à cerca realidade em que vivem.

O presente artigo busca discutir sobre a experiência do ensino das categorias geográficas para os três anos finais do ensino médio; relatando os instrumentos utilizados, e abordagem metodológica; discutir relação conteúdo programático e as dificuldades no processo de exercício da função por jovens professores ou professores jovens. 


\section{OS DESAFIOS DO ENSINO - COMO ENSINAR GEOGRAFIA?}

As categorias de análise da Geografia fazem parte da base para dos estudos que proporcionam melhor compreensão desta ciência. Milton Santos separou os conceitos geográficos em dois grupos: o primeiro, composto por objetos da natureza, como os rios, as montanhas e objetos resultante da ação humana; o segundo grupo pelo conjunto das relações que definem a sociedade. Já os Parâmetros Curriculares Nacionais (PCN):

“O espaço geográfico é historicamente produzido pelo homem, enquanto organiza econômica e socialmente sua sociedade” (BRASIL, 2000, p. 109).

Na busca desta articulação, a Geografia tem que trabalhar, de um lado, com os elementos e atributos naturais, procurando não só descrevê-los, mas entender as interações existentes entre eles; e de outro, verificar a maneira pela qual a sociedade está administrando e interferindo nos sistemas naturais.

Os estudos geográficos, ao possibilitarem a compreensão das relações sociedade-natureza, induzem à noção de cidadania, levando o aluno a analisar suas ações como agente ativo e passivo do meio ambiente e, portanto, capaz de transformar o espaço geográfico.

Considerando a necessidade de compreender os conceitos geográficos que baseiam o universo da Geografia, a proposta é de ter o cotidiano dos alunos como objeto de análise para qualificar, quantificar, analisar e construir os saberes das categorias: Lugar, Paisagem, Território e Região. Embora os termos estejam familiarizados no cotidiano popular - a teoria acadêmica os remete a outros significados - foi possível relacionar as contradições sociais e econômicas da cidade em que habitam.

Partimos do pressuposto de compreender o que vemos: a Paisagem. Para Vidal de La Blache: paisagem é aquilo que “[...] o olho abarca com o olhar”. Dessa forma, com detalhada descrição da composição do horizonte diário de cada um. Analisamos o bairro, o formato das casas, a disposição dos fios dos postes, a pavimentação das ruas e as ruas sem pavimentação; a arquitetura acabada e inacabada dos imóveis, o tamanho de cada um. De forma privilegiada, a escola em questão, possui vista com uma linda paisagem 'natural', que apesar de sofrer com a ação antrópica (queimada, pastoril, agricultura e afins), preserva a imagem de um vasto campo verde com arvores e vales. 
Ao verificar e constatar a existência destes elementos, realizamos entrevistas com moradores antigos, que descreveram como era o bairro antes da ocupação de moradores, como se deu o processo de ocupação.

"Aqui era tudo muito bom. As mulheres desciam ali no córrego - atrás da escola - para lavar louça, roupa e, até dar banho nas crianças.” - Iza, moradora do bairro Paulo VI.

Através destas investigações, foi possível comparar o contraste de uma paisagem com a outra: O 'natural' e o urbano. Então, decidimos traduzir em desenhos, conforme a percepção de cada aluno:

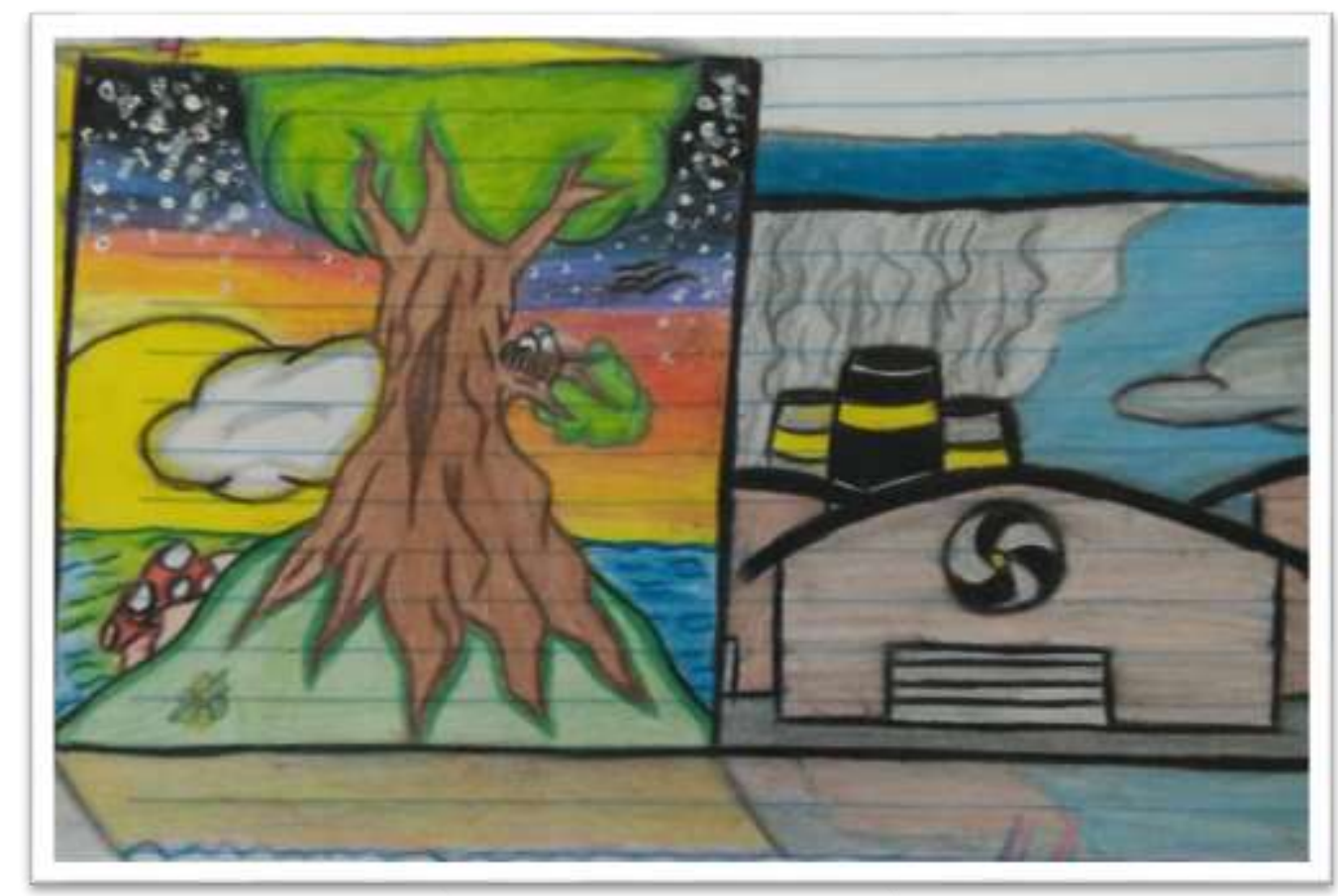

Fonte: Jennifer - aluna do segundo ano. E.E. Prof. Neidson Rodrigues

A idealização do 'natural' também é objeto de investigação. Muitos pensam em fazendas, florestas, lagos. Mas em conversa, foi possível constatar que poucos de fato tiveram oportunidade de conhecer a paisagem natural que desenharam. Muitos nunca saíram da cidade em que nasceram participando somente da vida urbana que lhe é possível; restrita em um quadrante chamado bairro, ou regional.

Partimos da paisagem e seguimos para o estudo do Território. Investigamos os tipos de poder e fronteiras existentes na escola, depois partimos para o bairro e assim até conseguirmos alcançar a escala da divisão Geopolítica Global. 
Inerente a este conceito, compreender as definições de fronteira e pode é fundamental. Para além das fronteiras físicas a que estamos acostumados - fronteiras naturais: rios, montanhas, ruas etc. - é fundamental discutir as fronteiras invisíveis que configuram as relações espaciais, e que estão diretamente relacionados com a essência da formação de um Território. Os processos que levaram a configuração do que são atualmente, as disputas, e diversas faces que o compõe. No contexto das relações sócio espaciais, o acesso a instrumentos de qualificação humana - cultura, esporte, lazer - é objeto de análise para a formação do pensamento crítico.

[...] O território é uma categoria importante quando se estuda a sua conceitualização ligada à formação econômica e social de uma nação. Nesse sentido, é o trabalho social que qualifica o espaço, gerando o território. Território não é apenas a configuração política de um Estado-Nação, mas sim o espaço construído pela formação social. (BRASIL, 2000, p. 111).

Localizada na periferia de Belo Horizonte, quase na divisa com outras cidades da região metropolitana, a escola analisada é muito distante do centro da capital, onde estão concentradas maior parte das agendas de entretenimento. Além disso, a possibilidade de formação continua se limita a localização geográfica. Os diversos programas de incentivo do governo e/ou da prefeitura localizam-se nas regionais Centro-Sul, e Leste; com isso, participar destes programas é economicamente inviável, limitando a meramente saber da existência dos mesmos, quando acontece.

Através do diálogo propiciado pelas aulas expositivas, foi possível identificar os territórios que fazem parte do cotidiano dos alunos nos locais de vivencia, de modo que a dinâmica local é alterada sempre que há alternância nestes 'poderes'. Um dos Territórios muito caracterizado pelos alunos é o tráfico, que definem padrões de comportamentos, ditam regras de conduta e deixa explícita a existência de comando. Sendo assim, quando as disputas por domínio de uma parte deste Território começam, é preciso que a população se adapte as imposições e aos efeitos que tais conflitos trazem.

Efeitos que atingem inclusive as instituições de ensino presente na mesma localidade. 'A gente já ficou sem aula, e teve até que sair mais cedo' - Aluna no $3^{\circ}$ ano

A espacialidade da Geografia possui possibilidade de análise conforme sua escala. Sendo assim, a categoria Lugar foi identificada como aquela porção territorial que transmite maior conforto emocional, que possui maior ligação afetiva e que traduz o sentimento de pertencimento. 
O interessante desta categoria foi embarcar no submundo de cada adolescente, poder ter acesso aos níveis afetivos que possuem. Muitos apresentaram uma porção da casa como o 'seu lugar', na maioria o quarto. No entanto, identificamos o papel da igreja e a influência da escola na formação e na construção de vida. Em alguns casos, a referência foram os cultos, como forma de refúgio e segurança; e a escola como sinônimo de liberdade de expressão, como possibilidade exploratória e de reencontro.

É fundamental que em experiências como tal o educador e a escola estejam abertos a receber uma sobrecarga emocional. $\mathrm{O}$ relato de alunos que perderam casas por eventos naturais, que não possuem moradias que lhes permitem ter um Lugar que possa ser chamado de seu, remete as discussões que questionam as razões de alguns terem casas tão exuberantes e outros não poderem ter uma cama.

Em meio às discussões sobre as condições de habitação, o questionamento sobre a existência de políticas públicas que possam amenizar este tipo de situação; de como os agentes políticos pode contribuir e, principalmente, como a organização e a solidariedade pode reduzir estes impactos.

A abstração é uma grande dificuldade quando se trata da aprendizagem significativa. Dessa forma, recursos como mapa é fundamental. Ao estudar a categoria Região, tivemos a possibilidade de identificar onde estamos no mapa, onde fica o bairro e a distância em que eles estavam do centro. Através da leitura dos mapas, identificamos a importância administrativa das divisões regionais, dos programas políticos voltados para cada grupo dividido conforme características econômicas, de proximidade geográfica, cultural.

Muitas constatações foram feitas, inclusive da necessidade de 'encurtar' as distâncias através das tecnologias de transporte e de informação; do mesmo modo a necessidade de fazer daquilo que chamamos de progresso, chegue até as áreas periféricas. Foi possível compreender os espaços privilegiados, quais as condições morfológicas em que estão situados, localizar onde as catástrofes naturais acontecem, e perceberam que estão intimamente ligadas as condições vulneráveis de habitação.

(...) o espaço organizado pelo homem é como as demais estruturas sociais, uma estrutura subordinadasubordinante. É como as outras instâncias, o espaço, embora submetido à lei da totalidade, dispõe de uma certa autonomia. (SANTOS, 1978, p. 145).

Manusear o mapa foi muito importante para a associação de onde estamos na cidade, no estado, no país e no mundo. Saber das nossas divisas, do tamanho do nosso 
Território Nacional, as diversidades e quais aplicabilidades de medidas administrativas que mitigam as desigualdades.

\section{CONCLUSÃO}

A aprendizagem com significado simboliza a aproximação da ciência com a realidade concreta, a materialização do indivíduo como agente de transformação e modelador do espaço em que habitam.

De forma coletiva, são os discentes responsáveis pela verificação se vai tudo bem ou se há necessidade de modificações. Colocá-los a par das necessidades humanas de forma consciente, é permitir que o futuro seja construído de forma crítica e responsável; olhar a paisagem que os cercam como um filme, e não uma fotografia, compreendendo os processos até chegar ao estado atual. Tudo isso faz parte de um aprendizado voltado para a formulação crítica e independente.

As necessidades humanas demandam grande esforço de adaptação de todo o ecossistema interligado. Quando um edifício é construído em um determinado bairro, os moradores são impactados, quando há a instalação de um equipamento público, quando os moradores reivindicam o a falta do mesmo. Todos estes aspectos são analisados de forma crítica, pois modificam a lógica de vida de uma comunidade inteira.

Assim, consideramos importante que concretização deste trabalho seja feita ao longo de todo o ano letivo, pois sendo os conceitos geográficos a base, os demais temas são associados de forma quase automática, despertando o aprendizado cognitivo e ativando saberes fundamentais.

\section{REFERÊNCIAS}

BRASIL. Secretaria de Educação Fundamental. Parâmetros Curriculares Nacionais: primeiro e segundo ciclos do ensino fundamental: Caracterização da Área de Geografia. Brasília: MEC/SEF, 2000.

LERNER, Delia. O ensino e o aprendizado escolar: argumentos contra a falsa oposição. In: CASTORINA, José A.; FERREIRO, Emilia; LERNER, Délia; OLIVEIRA, Marta Kohl de. Piaget e Vygotsky: novas contribuições para o debate. São Paulo, Ática, São Paulo, 1995. p.85-139.

MOREIRA, Marco; MASSINI, ELCIE. A aprendizagem significativa: a teoria de David Ausubel. São Paulo: Moraes, 1982. 
SACRISTÁN, J . Consciência e acção sobre a prática como libertação profissional dos professores. In: NOVOA, A. (org). Profissão professor. Portugal: Porto Ed, 1991. SANTOS, M. Por uma Geografia Nova. São Paulo: Hucitec, Edusp, 1978. 